\title{
Reconciling forest and tree conservation with food security
}

Forests and trees are a critical resource for hum communities. However,
conservation efforts to preve biodiversity loss incro prevent conflict with the rights and access of communities using forests for their livelihoods and crucially to meet their nutritional needs. Prof Terry Sunderland of the University of British Columbia, Vancouver, has long pointed Vo the importance of forests in wh buting to food secury work to bring stakeholders together is promoting a

sustainable landscape approach to management which allows. forests and trees to be

productive and meet dietary and livelihood needs while also contributing to biodiversity and climate change goals.

\section{प्र}

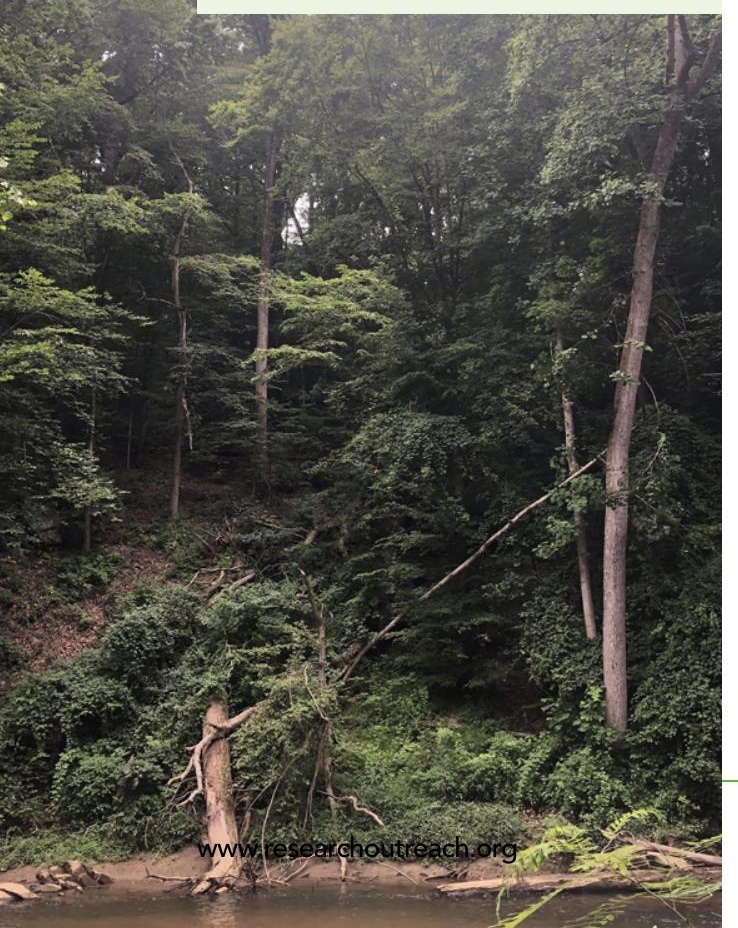

generating income to enable purchases from markets.

\section{DIETARY DIVERSITY AND HEALTH} In addition to quantity, both quality and diversity contribute to the overall nutritional value of a diet. Modern Foraging plants and hunting animals across a variety of habitats provided a varied and nutritious diet. While the development of agriculture increased the volume of available food, it also reduced dietary diversity a small variety of crops and livestock. Contemporary agriculture has likewise focused on producing large quantities of a relatively limited number of species. One result of this emphasis on quantity over diversity is that vast numbers of the global population are malnourished due to undernutrition and overweight and/or obese.
ofinutrient deficiencies.

Communities which still depend on or make use of forest and tree ecosystems have been shown to have a greater dietary diversity. Where indigenous communities have moved away from traditional diets towards a narrower range of foods, and often higher levels of fat, sugar, salt and refined carbohydrates, research has shown associated increases of non-communicable diseases like cardiovascular disease and diabetes. Over two billion people are estimated to suffer from deficiencies in essenti vitamins and minerals, known as them more susceptible to disease.

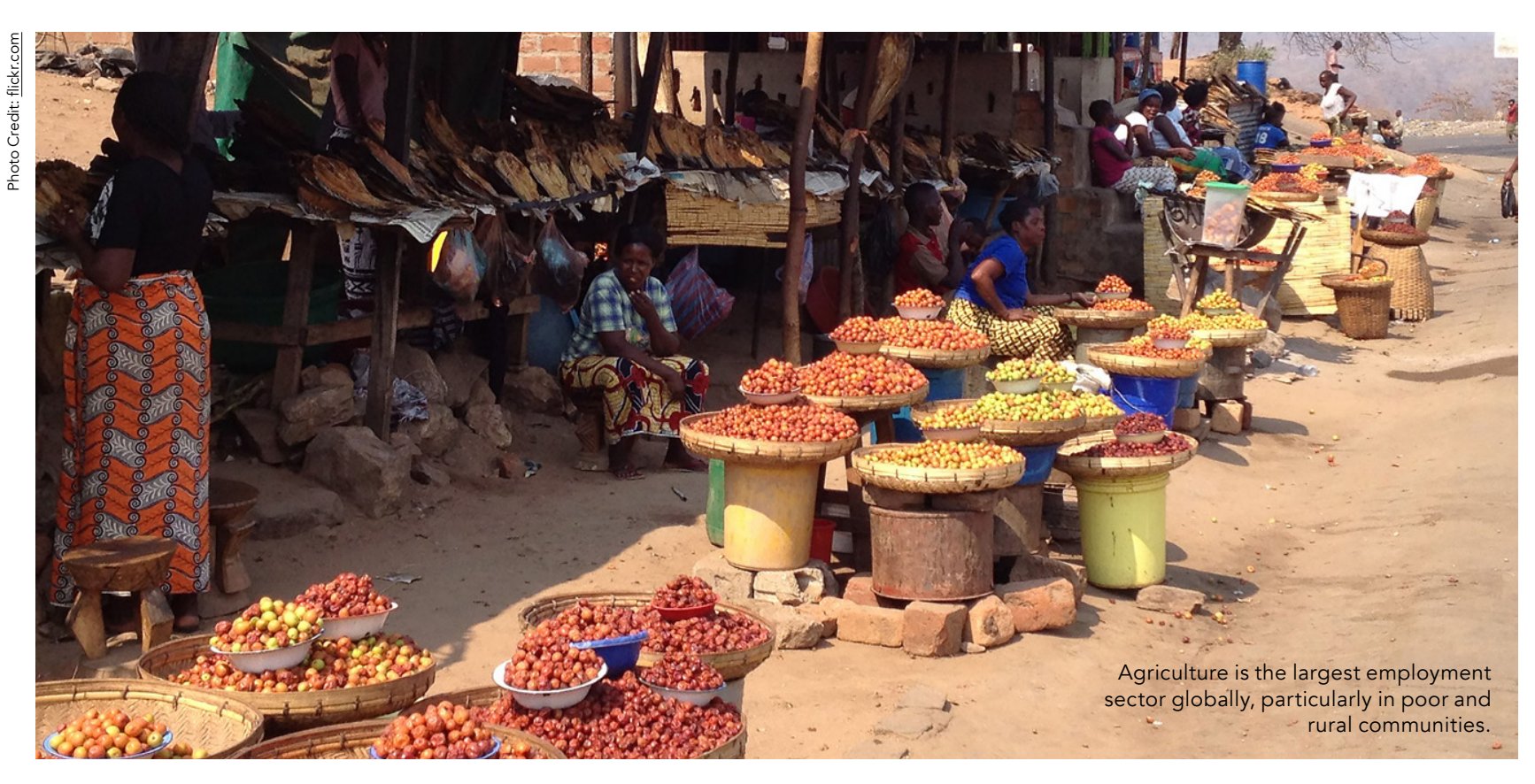

These trends are thought to be further traditional medicinal plants.

\section{AGRICULTURE AND
THE ENVIRONMENT}

Not only is the global food system regularly failing to provide good nutrition, modern agriculture has had a significant negative impact on biodiversity and the environment. The most visible negative impact is deforestation, with clear knock-on effects for both climate change and biodiversity loss. Agriculture also accounts for one third of greenhouse gas emissions with factors including reliance on fossil fuels and methane emissions from ruminants contribur
to this value. Soil erosion and degradation are the most recent area for concern as fertile land is lost and desertification increases.

The focus of modern agriculture on a few key crop and livestock species has led to a loss of genetic diversity both across and within species. Many wild relatives of crop and livestock species have been lost and today just 12 plant crops and 14 animal species provide $98 \%$ of global food needs. Loss of genetic diversity within a population leaves it vulnerable to inbreeding and less able to adapt particularly under current rapidly changing environmental conditions. Commercial monocultures support significantly less biodiversity,
and reliance on chemical control of pests
While the development of agriculture increased the volume of available food, it also reduced dietary diversity as communities focused on producing a small variety of crops and livestock.

also reduces the presence of beneficia pollinators and insect predators.

\section{CONSERVATION VS. RIGHTS} AND ACCESS Growing recognition of the impact of climate change and loss of biodivers have led to increasing levels of protection for areas of land and key seen as needing to be pristine and

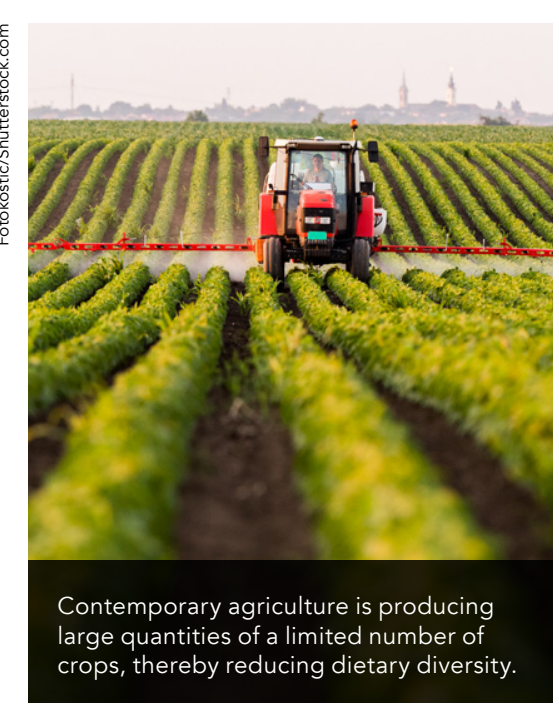

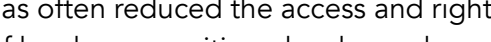

untouched and can fail to recognise that humans have been altering This fores and habitats for centuries. This form of biodiversity conservation forests and their res who depend on security and nutrition. Exclusion from protected areas not only prevents compound the reduction in food security through loss of access to water problems of livestock predation by Agriculture is also the largest employment sector globally, particularly in poor and rural communities; with conservation is increasingly vital.

LANDSCAPE APPROACHES Prof Sunderland is among scientists and stakeholders advocating land management which integrates ecologically friendly agriculture and conservation, while improving food
security and reducing malnutrition. wildlife, and loss of fuel for cooking therefore, reconciling rights and access sustainable landscape approaches to 


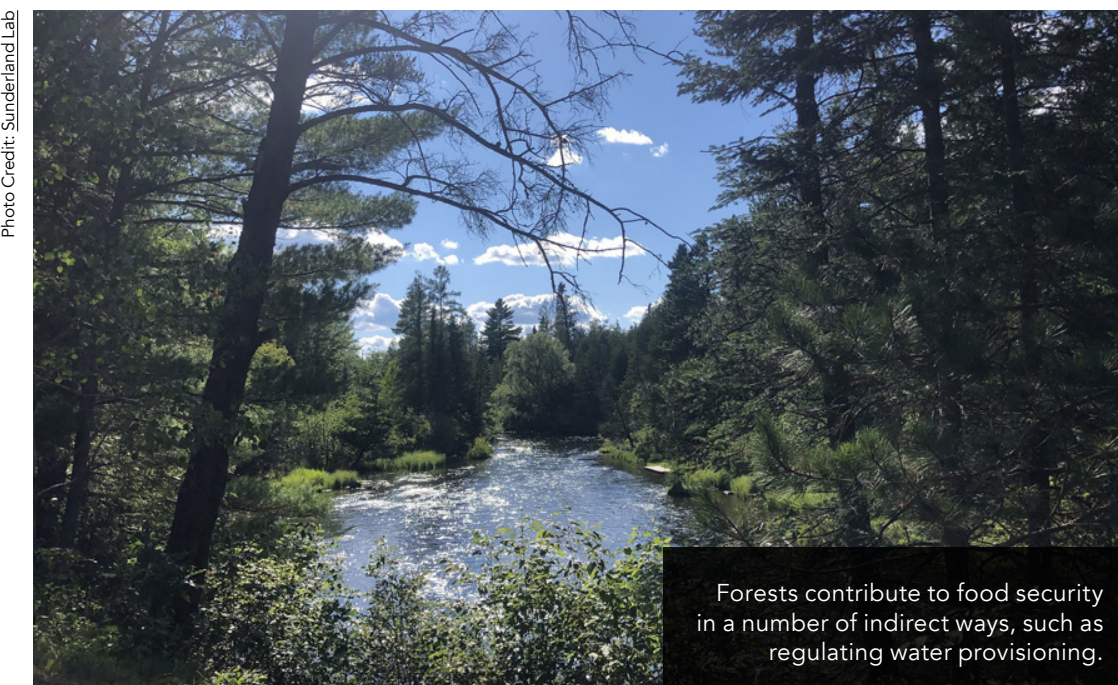

This form of biodiversity conservation has often reduced the access and rights of local communities who depend on

forests and their resources for food security and nutrition.

In a recent overview (Gergel et al.

$\begin{array}{ll}\text { a recent overview (Gergel et al. } & \text { foster agricultural production. Pathway } \\ 20 \text { ), Prof Sunderland and his co- } & \text { number three, the 'energy pathway', }\end{array}$ authors discussed evidence-based and theoretical links between landscape different land cover and their spatia distribution, and dietary diversity.

They proposed a framework of four direct and indirect (and sometimes interacting) pathways. The first, coined 'direct pathway', describes the direct contributions from forests such as vegetables and fish. The second, 'agroecological pathway' comprises ecosystem services that describes how fuelwood from forest' can facilitate the preparation of foods and thus ameliorate energy poverty of households. Finally, the 'income pathway' states that increased incom from selling forest products can provide rural households with a safety net and may lead to an improved, more diverse diet. Allogether, hese pathways emphasise that he aims of food security be mutually excosive This ineed not approach will be vital in tacking the current conflict between food security and conservation.

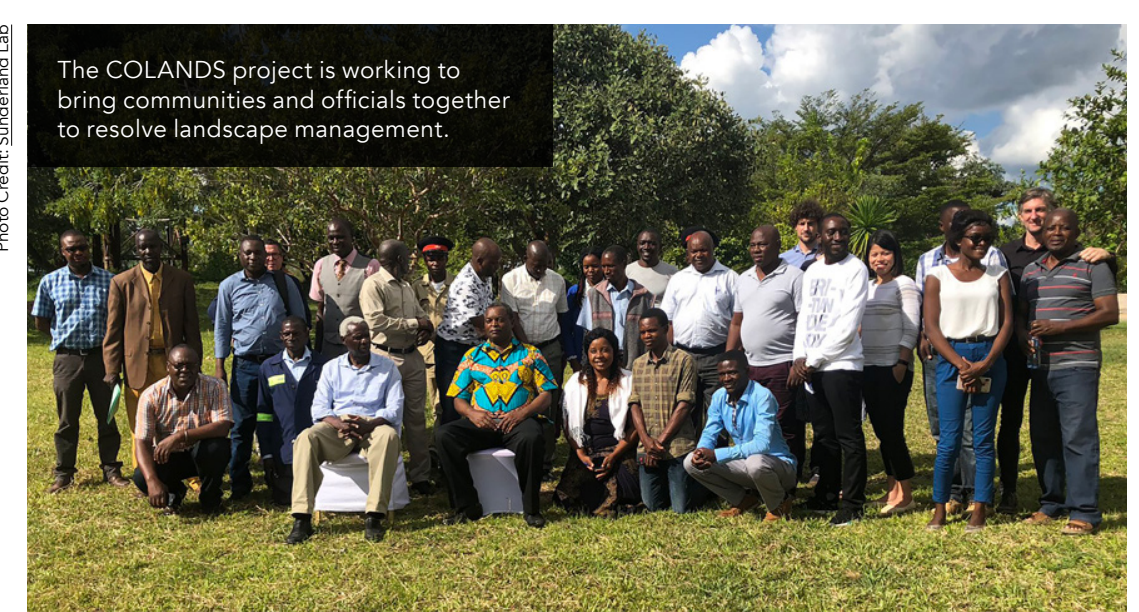

A commissioned report into 'Sustainable Forestry for Food Security High Level Panel of Experts on Food Security and Nutrition, chaired by Prof Sunderland, also made a series of global policy recommendations (http://www.fao.org/3/a-i7395e pdf to promote the inclusion of forests within food security discussion and policy. These recommendations have since been endorsed by governments and represent an important step towards the integration of forest conservation and food security

\section{PUTTING THEORY INTO ACTION} Working with The Centre for (CIFOR), Prof Sunderland is part of an ongoing project aiming to put the landscape to Operationalise Landscape Approaches for Nature, Development and Sustainability (COLANDS) is carrying out research and engaging with stakeholders with particular projects in Zambia, Ghana and Indonesia. In the Kalomo District of Zambia, maize and cattle production are vital for livelihoods. However, locals were facing eviction from forestry reserves by Zambia's Forestry Department. It is early days, but the COLANDS project is working to bring communities and officials together to resolve landscape management. As well as putting a landscape approach tho action, the COLANDS projects gather evidence of both positive and policy and practice agendas.

\section{FUTURE GLOBAL FOOD SYSTEMS} Forests and trees must continue to future food security and nutrition as well as to protect the rights and access of local communities. The work by Prof Sunderland also highlights the potential of forest and tree-based system to contribute to dietary diversity and quality, with potential benefits for micronutrient deficiency and diet related health. The global food system of the future must move away from increasing production to increasing quality and diversity, using sustainable forestry and agricultural practices, which beneft both biod

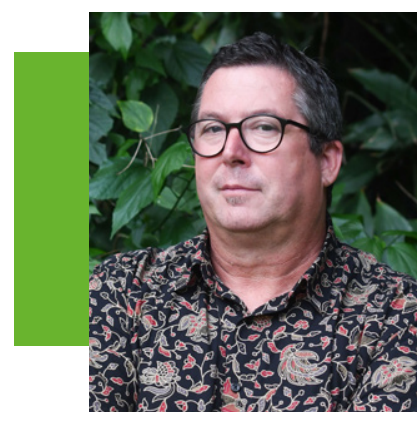

\section{Behind the Research}

\section{Dr Terry Sunderland}

W: terry.sunderland@ubc.ca T: +17788716483 W: https://sunderlandlab.forestry.ubc.ca/

\section{Research Objectives}

Prof Sunderland is gathering evidence for the mportance of forests and trees in the attanmment of land management.

\section{Detail}

Terry Sunderland

Faculty of Forestry

University of British Columbia

2424 Main Mall

Vancouver V6T 1 Z4

Bio

Terry Sunderland is a Professor of Tropical Forestry at the University of British Columbia, Canada and a Senior Research Associate at the Centre for International Forestry Research, Indonesia.

Funding

United States Agency for International Development

-

Collaborators

orest Research

- High Level Panel of Expe

ts on Food Security

and Nutrition (HLPE)

UBC THE UNIVERSITY OF BRITISH COLUMBIA

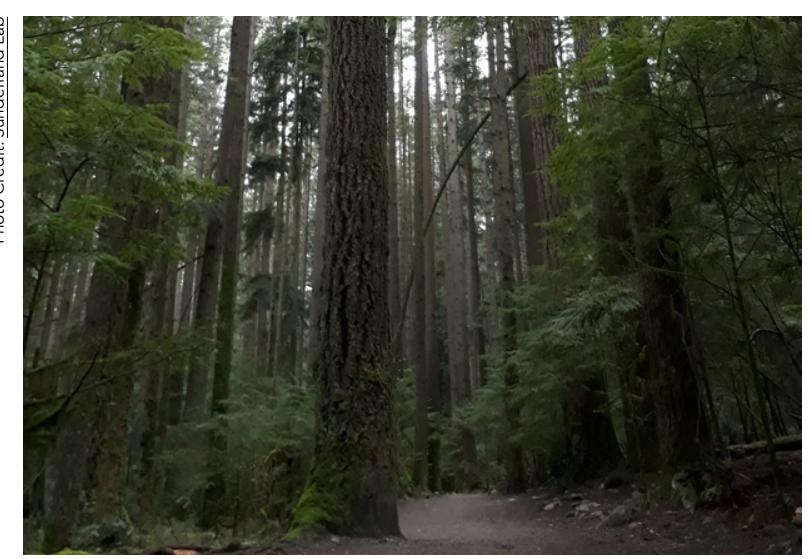

\section{References}

Centre for International Forestry Research (CIFOR) (2020) Collaboration to Operationalise Landscape Approaches for Nature, Development and Sustainability (COLANDS). Available at: https://www2.cifor.org/colands/[Accessed $22 / 07 / 20$

Gergel, S., Powell, B., Baudron, F., Wood, S.L.R. Rhemtulla, J.M., Kennedy, G., Rasmussen, L.V., Ickowitz, A., Fagan, M.E., Smithwick, E.A.H., Ranieri, J., Wood, Links between Landscape Diversity and Diet Diversity; A Roadmap for Transdisciplinary Research. BioScience, 70 563-575. Available at: https://doi.org/10.1093/biosci/ bia 048

High Level Panel of Experts on Food Security and Nutrition (HLPE) (2017). Sustainable forestry for food security and nutrition. Available at: http://www.fao.org/cfs/cfs-hlpe/ reports/en/ [Accessed 22/07/20]

Interconnecting Forests, Science and People (IUFRO) (2015). World Series Vol 33 - Forests, Trees and Landscapes for Food Security and Nutrition. A Global Assessment Report. Available at: https://www.iufro.org publications/series/world-series/article/2015/05/06/ world-series-vol-33-forests-trees-and-landscapes-for-food

Sunderland, T.C. and Vasquez, W. (2020). Forest Conservation, Rights, and Diets: Untangling the Issues. Frontiers in Forest and Global Change, 3, 29. Available at: https://doi.org/10.3389/ffgc.2020.00029

\section{Personal Response}

Can landscape approaches be applied to other habitats as well as forests and trees?

II Landscape approaches can be applied in any context where multiple land uses are in concert, or conflict. These can include non-forested areas such as grasslands and savannahs, but can also be applied help understand the process: https://www.pnas.org/ content/110/21/8349 